\title{
Solid-State Conformation, Molecular Packing, and Electrical and Optical Properties of Processable $\beta$-Methylated Sexithiophenes
}

\author{
Giovanna Barbarella, ${ }^{*}, \dagger$ Massimo Zambianchi, ${ }^{\dagger}$ Luciano Antolini,,${ }^{\ddagger}$ Paolo Ostoja,, \\ Piera Maccagnani, ${ }^{\S}$ Alessandro Bongini," Elisabeth A. Marseglia, ${ }^{\perp}$ Emilio Tedesco, ${ }^{\perp}$ \\ Giuseppe Gigli," and Roberto Cingolani"
}

\author{
Contribution from the Consiglio Nazionale Ricerche, ICoCEA, Via Gobetti 101, 40129 Bologna, Italy, \\ Dipartimento di Chimica, Università di Modena, Via Campi 183, 41100 Modena, Italy, \\ Consiglio Nazionale Ricerche, LAMEL, Via Gobetti 101, 40129 Bologna, Italy, Dipartimento di Chimica \\ G. Ciamician, Università di Bologna, Via Selmi 2, 40126 Bologna, Italy, Cavendish Laboratory, \\ University of Cambridge, Madingley Road, Cambridge, United Kingdom, CB30HE, and \\ Istituto Nazionale di Fisica della Materia, Dipartimento di Scienza dei Materiali, Università di Lecce, \\ Via Arnesano, 73100 Lecce, Italy
}

Received May 17, 1999. Revised Manuscript Received June 28, 1999

\begin{abstract}
Newly synthesized sexithiophenes, di- and tetramethylated at the $\beta$-positions, are shown to be soluble and processable compounds, giving single crystals suitable for X-ray structure determination. The molecular packing was characterized in terms of crystal cohesion and short $\mathrm{C}-\mathrm{H} \cdots \mathrm{S}$ and $\mathrm{C}-\mathrm{H} \cdots \pi$ intermolecular distances. In particular, the dimethylated sexithiophene displayed very compressed molecular packing and a thin film field effect transistor, fabricated with this material, was characterized by high charge mobility [ $2 \times$ $\left.10^{-2} \mathrm{~cm}^{2} /(\mathrm{V} \mathrm{s})\right]$. The tetramethylated compound crystallizes at room temperature in two different systems and with different conformations. The conformational polymorphs, which are easily interconverted at room temperature, are characterized by different wavelengths of light emission and excitation decay rates.
\end{abstract}

The study of the electrical and optical properties of conjugated organic oligomers and polymers has emerged in the last years as an important branch of the science of new materials. ${ }^{1}$ One of the most attractive aspects of organic materials is the easy, fine, and, in the end, low-cost tuning of the properties through the synthesis of families of variously functionalized compounds.

\footnotetext{
Consiglio Nazionale Ricerche, ICoCEA.

† Università di Modena.

$\S$ Consiglio Nazionale Ricerche, LAMEL.

"Università di Bologna.

$\perp$ University of Cambridge.

\# Università di Lecce.
}

(1) (a) Nalwa, H. S., Ed. Handbook of organic conductive molecules and polymers; John Wiley \& Sons: Chichester, 1997; Vols. 1-4. (b) Skotheim, T. A., Elsenbaumer R. L., Reynolds, J. R., Eds. Handbook of conductive polymers; Marcel Dekker: New York, 1998. (c) Müllen, K., Wegner, G., Eds. Electronic Materials: The Oligomer Approach; WileyVCH: New York, 1998.

(2) (a) Garnier, F.; Horowitz, G.; Peng, X. Z.; Fichou, D. Adv. Mater. 1990, 2, 381. (b) Garnier, F.; Yassar, A.; Hajlaoui, R.; Horowitz, G.; Deloffre, F.; Servet, B.; Ries, S.; Alnot, P. J. Am. Chem. Soc. 1993, 115, 8716. (c) Garnier, F. Pure Appl. Chem. 1996, 68, 1455. (d) Horowitz, G.; Bachet, B.; Yassar, A.; Lang, P.; Demanze, F.; Fave, J. L.; Garnier, F. Chem. Mater. 1995, 7, 1337. (e) Servet, B.; Horowitz, G.; Ries, S.; Lagorsse, O.; Alnot, P.; Yassar, A.; Deloffre, F.; Srivastava, P.; Hajlaoui, R.; Lang, P.; Garnier, F. Chem. Mater. 1994, 6, 1809. (f) Hajlaoui, R.; Horowitz, G.; Garnier, F.; Arche-Brouchet, A.; Laigre, L.; El Kassmi, A.; Demanze, F.; Kouki, F. Adv. Mater. 1997, 9, 389. (g) Garnier, F.; Hajlaoui, R.; El Kassmi, A.; Horowitz, G.; Laigre, L.; Porzio, W.; Armanini, M.; Provasoli, F. Chem. Mater. 1998, 10, 3334. (h) Li, X. C.; Sirringhaus, H.; Garnier, F.; Holmes, A. B.; Moratti, S. C.; Feeder, N.; Clegg, W.; Teat, S. J.; Friend, R. H. J. Am. Chem. Soc. 1998, 120, 2206. (i) Horowitz, G.; Kouki, F.; Garnier, F. Adv. Mater. 1998, 10, 382. (1) Horowitz, G.; Garnier, F.; Yassar, A.; Hajlaoui, R.; Kouki, F. Adv. Mater. 1996, 8, 52. (m) Yassar, A.; Garnier. F.; Deloffre, F.; Horowitz, G.; Ricard, L. Adv. Mater. 1994, 6, 660. (n) Horowitz, G.; Kouki, F.; El Kassmi, A.; Valat, P.; Wintgens, V.; Garnier, F. Adv. Mater. 1999, 11, 234. (o) Antolini, L.; Horowitz, G.; Kouki, F.; Garnier, F. Adv. Mater. 1998. 10, 381. (p) Horowitz, G. Adv. Mater. 1998, 10,365 .
The richness of thiophene chemistry and the chemical stability of thiophene derivatives have made thiophene-based materials one of the most promising families for application in electronics and photonics. ${ }^{1}$

Oligothiophenes are recognized as being among the best candidates for application in large-area thin film field effect transistors (TFTs). ${ }^{2,3}$ Unsubstituted sexithiophene (T6), a p-type (hole transporting) semiconductor material, may reach charge mobility values on the order of that of amorphous silicon and achieve high current on/off ratios, ${ }^{2 e, 1,3 a, c, 4}$ which are prerequisites for application in all-plastic, flexible devices. It has been demonstrated that the high charge mobility of T6 is due to the great molecular ordering achieved in the solid state. ${ }^{2 \mathrm{e}}$ Recently, it has been reported that the photoluminescence properties of T6 are also dependent on the crystalline structure. ${ }^{2 n}$ Unfortunately, unsubstituted sexithiophene is scarcely soluble and this has prompted investigation on shorter homologues ${ }^{2 \mathrm{e}-\mathrm{g}, 3 \mathrm{f}}$ or sexithiophene analogues, ${ }^{3 g-h, 5}$ which are processable. Processability is indeed a key issue for liquid-phase fabrication of lowcost devices.

(3) (a) Dodalabapur, A.; Torsi, L.; Katz, H. E. Science 1995, 268, 270 (b) Siegrist, T.; Fleming, R. M.; Haddon, R. C.; Laudise, R. A.; Lovinger, A. J.; Katz, H. E.; Bridenbaugh, P.; Davis, D. D. J. Mater. Res. 1995, 10, 2170. (c) Dodalabapur, A.; Katz, H. E.; Torsi, L. Adv. Mater. 1996, 8, 853. (d) Katz, H. E. J. Mater. Chem. 1997, 7, 369. (e) Katz, H. E.; Laquindanum, J. G.; Lovinger, A. J. Chem. Mater. 1998, 10, 633. (f) Katz, H. E.; Lovinger, A. J.; Laquindanum, J. G. Chem. Mater. 1998, 10, 457. (g) Laquindanum, J. G.; Katz, H. E.; Lovinger, A. J. J. Am. Chem. Soc. 1998, 120, 664. (h) Li, W.; Katz, H. E.; Lovinger, A. J.; Laquindanum, J. G. Chem. Mater. 1999, 11, 458. (1) Siegrist, T.; Kloc, C.; Laudise, R. A.; Katz, H. E.; Haddon, R. C. Adv. Mater. 1998, 10, 379.

(4) Shön, J. H.; Kloc, Ch.; Laudise, R. A.; Batlogg, B. Appl. Phys. Lett. 1998, 73, 3574.

(5) Sirringhaus, H.; Friend, R. H.; Li, X. C.; Moratti, S. C.; Holmes, A. B.; Feeder, N. Appl. Phys. Lett. 1997, 71, 3871. 
Functionalization increases the solubility of sexithiophene but may subvert the solid-state molecular ordering preferences required for achieving high charge mobilities. The question of how to make oligothiophenes soluble and processable through the introduction of substituents into the conjugated backbone, while maintaining their ability to self-organize in the solid state with a great structural order is still open. The problem is related to the more general question of how to design molecules capable of self-organizing in the desired supramolecular array in the solid state ${ }^{6}$ and displaying the desired electrical and optical properties.

In the lack of well-established a priori criteria, the most straightforward way to obtain information on the supramolecular organization of oligothiophenes in the solid state is to determine their single-crystal X-ray structure. The single-crystal represents the upper limit of achievable purity and molecular organization of the material. Dissecting the elements governing the crystal packing gives information about the forces presiding over the organization of the same molecules in the thin films used for fabricating the devices. Governing these forces and understanding the relationship between the type of supramolecular organization and the electrical and optical properties of the film, are necessary steps to bridge the gap from the design and the synthesis of molecules to their use in electrical and optical devices. However, oligothiophenes are difficult to crystallize and despite the great improvements over the past few years, only a few single-crystal X-ray structures of the longer oligothiophenes have been published so far. $2 \mathrm{~d}, 3 \mathrm{~b}, 7$

We report here a study on two newly synthesized soluble and processable $\beta$-methyl substituted sexithiophenes $\mathbf{1}$ and $\mathbf{2}$, which give single crystals suitable for X-ray structure determination.
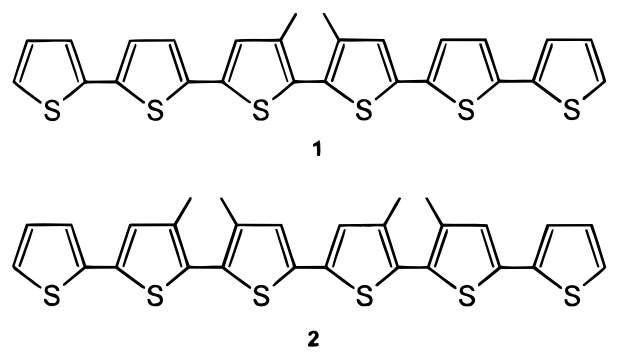

The packing characteristics of $\mathbf{1}$ suggested the utility of testing its electrical properties, and this was done through the fabrication of a thin film field effect transistor. Sexithiophene $\mathbf{2}$ was characterized by conformational polymorphism. Data on the photoluminescence properties of the two polymorphs are reported.

\section{Results}

I. Single-Crystal X-ray Structure Determinations. Figure 1 shows the ORTEP drawing and the molecular packing of sexithiophene 1. Sexithiophene $\mathbf{2}$ gives rise to conformational polymorphism, resulting in a monoclinic (2M) and a triclinic (2T) form. The ORTEP drawings and the molecular packing of $\mathbf{2 M}$ and $\mathbf{2 T}$ are given in Figures 2 and 3, respectively, while the most relevant structural features of $\mathbf{1}, \mathbf{2 M}$, and $\mathbf{2 T}$ are given in Table 1. The nomenclature used in the drawings is related to molecular symmetry and does not correspond to the IUPAC nomenclature used in the Experimental Section.

(6) (a) Desiraju, G. R. Angew. Chem., Int. Ed. Engl. 1995, 34, 23112327. (b) Desiraju, G. R. The Crystal as a Supramolecular Entity; John Wiley \& Sons: Chichester, 1997.
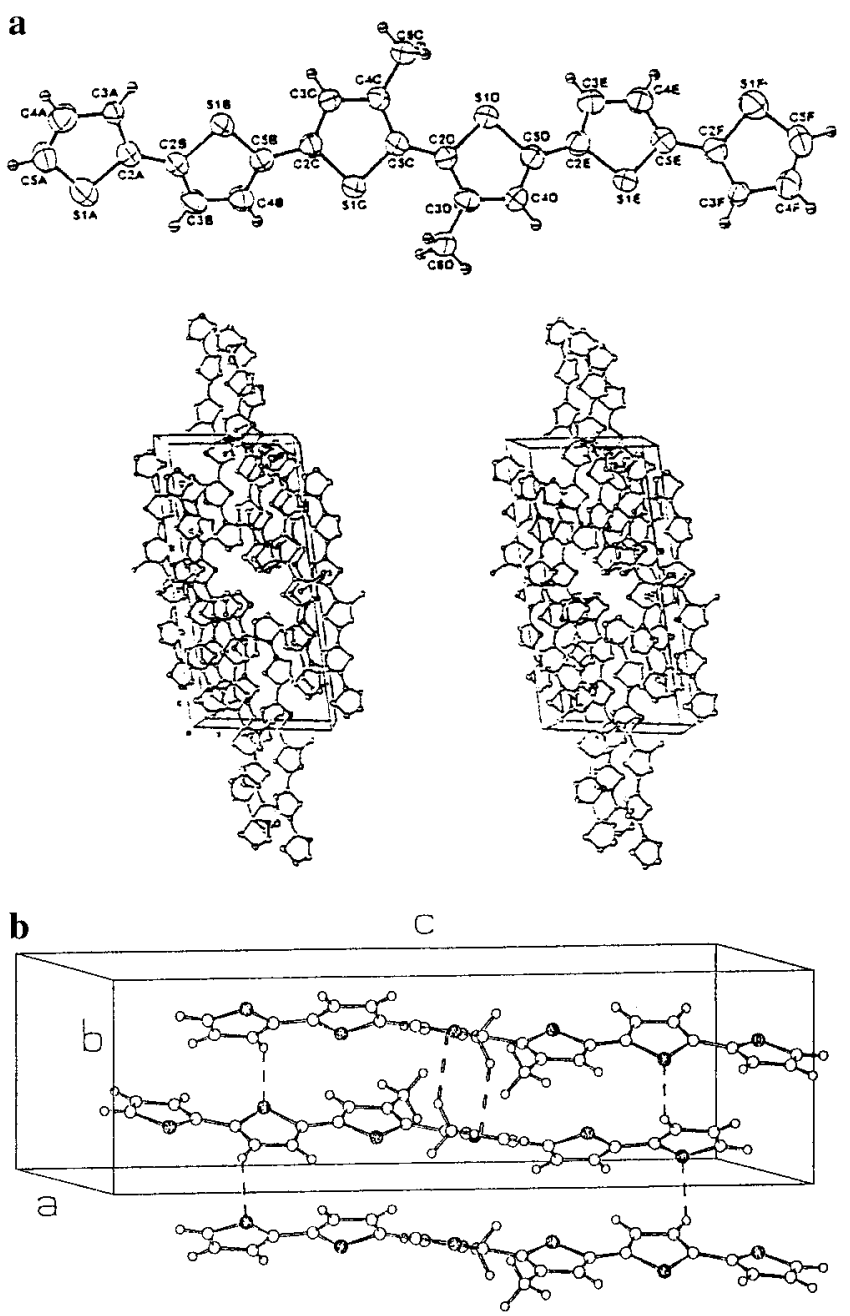

Figure 1. (a) Molecular structure and (b) crystal packing $(\mathrm{C}-\mathrm{H} \cdots \mathrm{S}$ intermolecular interactions in black, $\mathrm{C}-\mathrm{H} \cdots \pi$ in white) of sexithiophene 1.

Table 2 reports the total packing potential energies (ppe), the packing coefficients $(\mathrm{pc})$ and the molecular volumes $\left(V_{\mathrm{mol}}\right)$ of $\mathbf{1}$ and $\mathbf{2}$, together with the corresponding values for the low- $2 \mathrm{~d}$ and high ${ }^{3 b}$ temperature forms of unsubstituted sexithiophene (named hereafter T6LT and T6HT, respectively) for comparison.

The thiophene rings of $\mathbf{1}, \mathbf{2 T}$, and $\mathbf{2 M}$ are fully planar, within the accuracy of atomic positions, as commonly found in oligothiophenes and the corresponding bond distances and angles compare well with those reported for oligothiophenes of known structure. ${ }^{2,3,7,8}$ The X-ray structure of $\mathbf{1}$ is built up on one crystallographically independent molecule, whereas the asymmetric unit of $\mathbf{2 T}$ and $\mathbf{2 M}$ contains one-half molecule.

Sexithiophene $\mathbf{1}$ exists in the all-anti conformation. Only the first two rings (A and B in Figure 1a) are coplanar. The molecules of $\mathbf{1}$ stack along the shortest cell axis $b$, roughly parallel to the $a c$ plane, and short $\mathrm{C}-\mathrm{H} \cdots \mathrm{S}$ and $\mathrm{C}-\mathrm{H} \cdots \pi$ intermolecular interactions are present between these stacking molecules (Figure 1b). The $\mathrm{C}-\mathrm{H} \cdots \mathrm{S}$ short distances are 2.90 and $2.92 \AA$, while in the $\mathrm{C}-\mathrm{H} \cdots \pi$ type of interaction, which involves the methyl hydrogens of one molecule and the $\pi$-electron cloud of the neighboring thiophene, a contact of 2.59 $\AA$ is found.

In both $\mathbf{2 M}$ and $\mathbf{2 T}$ the outer rings are in the anti orientation, whereas the inner rings are exactly trans coplanar, due to the presence of the inversion center (Figure 2). 2T is characterized 

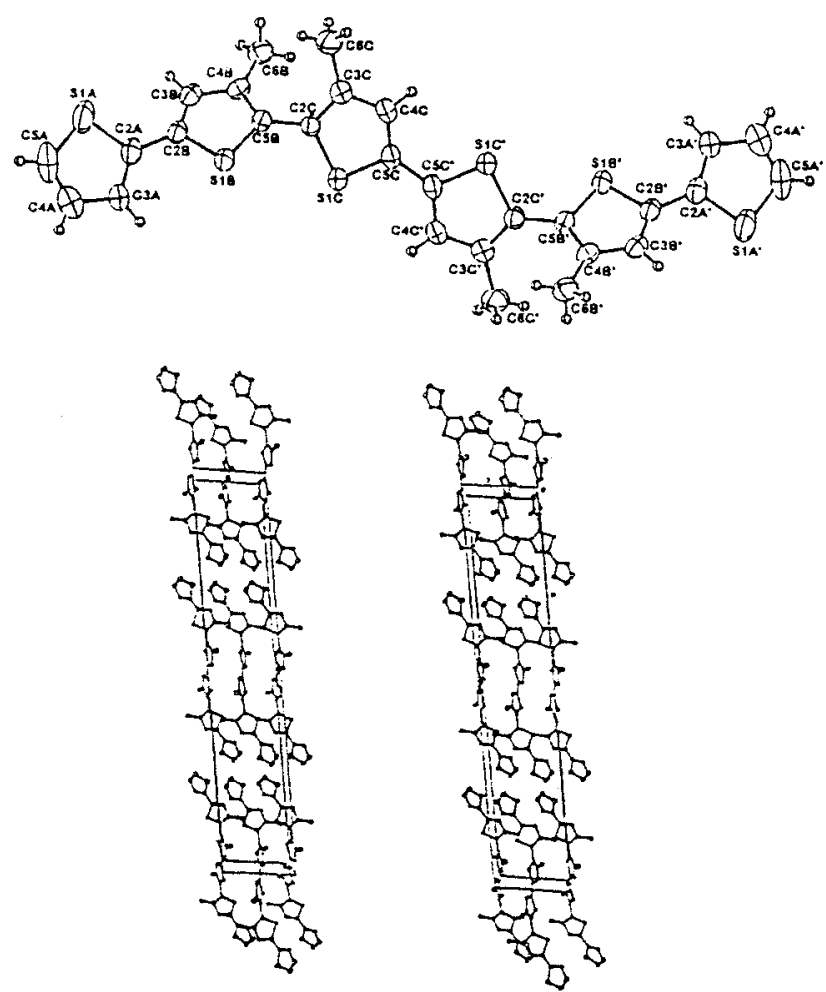

Figure 2. Molecular structure and stereoview of the crystal packing of the monoclinic form of sexithiophene 2 (2M).
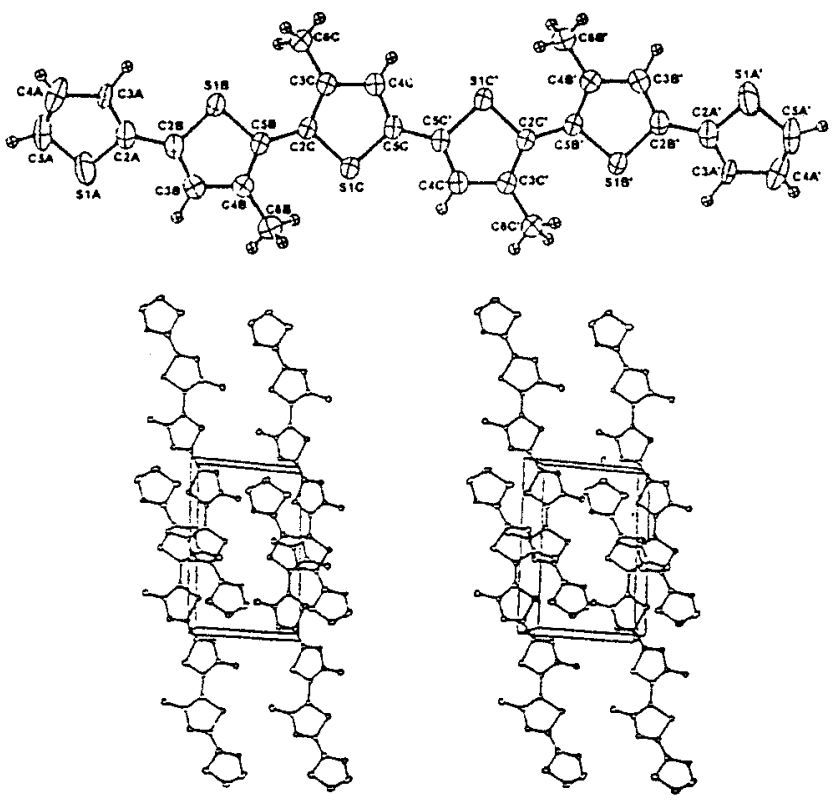

Figure 3. Molecular structure and stereoview of the crystal packing of the triclinic form of sexithiophene 2 (2T).

by statistical disorder involving the terminal thiophene rings, and arising from a $180^{\circ}$ rotation around their inter-ring $\mathrm{C}-\mathrm{C}$ bond (see Experimental Section). The type of rotational disorder, which leads to syn conformation, and the extent of statistical disorder (79\% for the prevailing anti conformation) are the same as that already observed in several oligothiophenes of different lengths. ${ }^{2 \mathrm{~d}, 3 \mathrm{~b}, 7,8}$

(7) (a) Herrema, J. K.; Wildeman, J.; van Bolhuis, F.; Hadziioannou, G. Synth. Met. 1993, 60, 239. (b) Liao, J. H.; Benz, M.; LeGoff, E.; Kanatzidis, G. Adv. Mater. 1994, 6, 135. (c) Fichou, D.; Bachet, B.; Demanze, F.; Billy, I.; Horowitz, G.; Garnier, F. Adv. Mater. 1996, 8, 500. (d) Yassar, A.; Garnier, F.; Deloffre, F.; Horowitz, G.; Ricard, L. Adv. Mater. 1994, 6, 660.
Table 1. Summary of Relevant Structural Features of Sexithiophenes $1,2 \mathrm{M}$, and $2 \mathrm{~T}$

\begin{tabular}{|c|c|c|c|}
\hline & 1 & $2 \mathrm{M}$ & $\mathbf{2} \mathbf{T}^{a}$ \\
\hline crystal system & monoclinic & monoclinic & triclinic \\
\hline space group & $P 2_{1} / n$ & $C 2 / c$ & $\mathrm{P} \overline{1}$ \\
\hline $\begin{array}{l}\text { asymmetric unit } \\
\text { contents (molecules) }\end{array}$ & 1 & $1 / 2^{b}$ & $1 / 2^{b}$ \\
\hline calculated density $\left(\mathrm{mg} / \mathrm{m}^{3}\right)$ & 1.474 & 1.417 & 1.459 \\
\hline $\begin{array}{l}\text { mean } \mathrm{C}-\mathrm{S} \text { distance }(\AA) \\
\text { in outer rings }\end{array}$ & $1.697(6)$ & $1.705(5)$ & $1.699(4)$ \\
\hline $\begin{array}{l}\text { mean } \mathrm{C}-\mathrm{S} \text { distance }(\AA) \\
\text { in inner rings }\end{array}$ & $1.730(5)$ & $1.732(3)$ & $1.728(3)$ \\
\hline $\begin{array}{l}\text { mean } \mathrm{C}-\mathrm{C} \text { inter-ring } \\
\text { distance }(\AA)\end{array}$ & $1.459(7)$ & $1.460(5)$ & $1.455(4)$ \\
\hline $\mathrm{S}-\mathrm{C}-\mathrm{C}-\mathrm{S}$ torsion angles $(\mathrm{E})$ & $180.0(3)$ & $159.3(2)$ & $162.3(2)$ \\
\hline \multirow[t]{4}{*}{ between adjacent rings ${ }^{c}$} & $155.0(3)$ & $52.2(3)$ & $153.3(1)$ \\
\hline & 154.1(3) & $180^{*}$ & $180^{*}$ \\
\hline & $174.4(3)$ & $-52.2(3)^{b}$ & $-153.3(1)^{b}$ \\
\hline & $-163.4(3)$ & $-159.3(2)^{b}$ & $-162.3(2)^{b}$ \\
\hline
\end{tabular}

${ }^{a}$ For this compound, affected by rotational disorder involving the outer rings, only the values relative to the prevailing anti orientation were reported. ${ }^{b}$ Due to the presence of the molecular center of symmetry. ${ }^{c}$ Starting from A-labeled ones in Figures $1-3$.

Table 2. Packing Potential Energies (ppe, $\mathrm{kcal} \mathrm{mol}^{-1}$ ), Packing Coefficients $(\mathrm{pc})$ and Molecular Volumes $\left(V_{\mathrm{mol}}\right)$ of $1,2 \mathrm{M}$, and $2 \mathrm{~T}$ and of the High ${ }^{3 \mathrm{~b}}$ and $\mathrm{Low}^{2 \mathrm{~d}}$ Temperature Forms of Unsubstituted Sexithiophene, T6HT and T6LT

\begin{tabular}{lccc}
\hline compound & ppe & pc & $V_{\text {mol }} \AA^{3}$ \\
\hline $\mathbf{1}$ & -119.7 & 0.72 & 422 \\
$\mathbf{2 M}$ & -114.1 & 0.70 & 455 \\
$\mathbf{2 T}$ & -127.9 & 0.73 & 455 \\
T6HT & -120.6 & 0.73 & 390 \\
T6LT & -116.5 & 0.74 & 389
\end{tabular}

${ }^{a}$ Values relative to the prevailing conformation with the outer rings in the anti arrangement.

The polymorphism arises from two completely different orientations of the methyl-substituted rings, which display a strongly twisted syn conformation in $\mathbf{2 M}$, and a less tilted anti conformation in 2T. To our knowledge, the only other case of conformational polymorphism reported for oligothiophenes is that of $3,3^{\prime}, 4^{\prime \prime}, 3^{\prime \prime \prime}$-tetrakis(methylsulfanyl)-2,2':1',2": $1^{\prime \prime}, 2^{\prime \prime \prime}$-quaterthiophene (TMSQ), in which the $\mathrm{SCH}_{3}$ groups are in the same regiochemical arrangement as the $\mathrm{CH}_{3}$ groups of the four inner rings of $1 .^{8 \mathrm{e}, \mathrm{f}}$ The polymorphism observed for $\mathbf{2}$ is strictly of the same type as that of TMSQ. ${ }^{8 \mathrm{e}, \mathrm{f}}$ It is also remarkable that the conformation and the geometry of the substituted fragment of $\mathbf{2 M}$ is exactly the same as that of the tetramethyl-substituted quaterthiophene with the same regiochemistry of substitution. ${ }^{8 \mathrm{~d}}$ This is even more remarkable if one considers that the syn arrangement between thiophene rings is uncommon in oligothienyls. ${ }^{2 \mathrm{~d}, 3 \mathrm{~b}, 7,8}$

The molecular packing of $\mathbf{2 M}$ (Figure 2) is such that the molecules stack along the $c$ axis and their more coplanar moieties roughly face, two at time, the corresponding subunits of symmetry related molecules. The molecular packing of $\mathbf{2 T}$ (Figure 3) may be labeled as a "sandwich" type, due to its triclinic unit cell. The molecules approximately face each other in the $a c$ plane, but with a half molecule shift along the $c$ direction. In both polymorphs short $\mathrm{C}-\mathrm{H} \cdots \mathrm{S}$ intermolecular interactions are found.

(8) (a) Hotta, S.; Waragai, K. J. Mater. Chem. 1991, 1, 831. (b) Visser, G. J.; Heeres, J.; Wolters, J.; Vos, A. Acta Crystallogr., Sect. B 1968, B24, 467. (c) Chaloner, P. A.; Gunatunga, S. R.; Hitchcock, P. B. J. Chem. Soc., Perkin Trans. 2, 1997, 1197. (d) Barbarella, G.; Zambianchi, M.; Bongini, A.; Antolini, L. Adv. Mater. 1993, 1, 834. (e) Barbarella, G.; Zambianchi, M.; Di Toro, R.; Colonna, M.; Antolini, L.; Bongini, A. Adv. Mater. 1996, 8, 327. (f) Barbarella, G.; Zambianchi, M.; del Fresno I Marimon, M.; Antolini, L.; Bongini, A. Adv. Mater. 1997, 9, 484. 

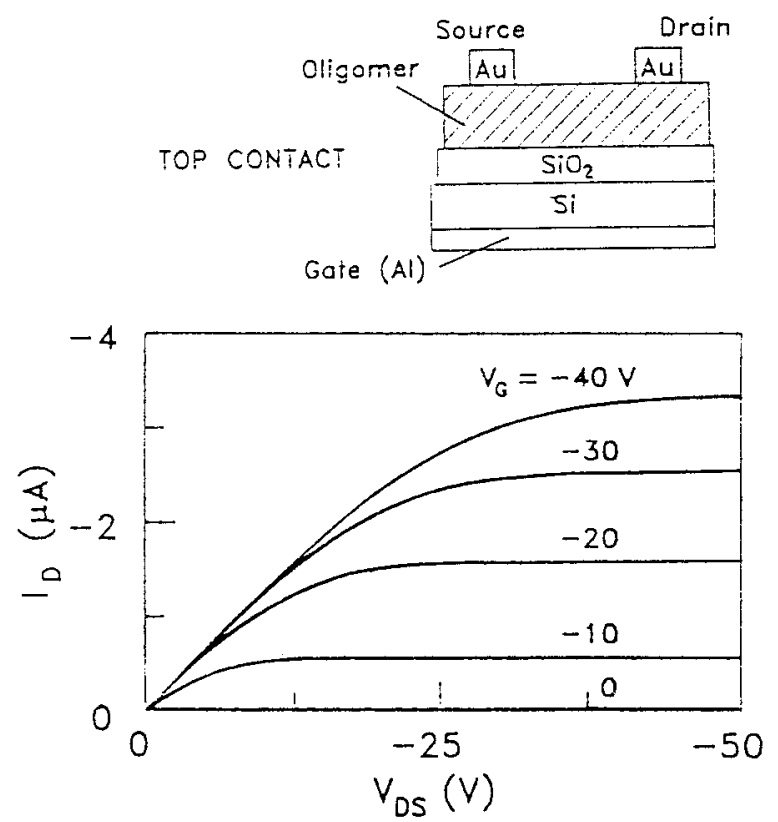

Figure 4. Source-drain current vs voltage $\left(I_{\mathrm{D}}\right.$ vs $\left.V_{\mathrm{DS}}\right)$ characteristics for different gate voltages of the thin film field effect transistor fabricated with sexithiophene $\mathbf{1}$. The film was vacuum deposited on a substrate at $T=80^{\circ} \mathrm{C}$. The scheme of the device used ("top"-contact geometry) is also given.

Finally, we observed that crystallization always afforded a mixture of the yellow (monoclinic) and orange (triclinic) crystals of 2. 2M was always formed in greater quantities than 2T. 2M and $\mathbf{2 T}$ were easily interconverted at room temperature by changing the solvent, but a detailed study of this phenomenon was beyond the purposes of this study.

The comparison of packing coefficients and energies for all the structures considered in Table 2 gives some insight on the crystal efficiency of these compounds. A more planar conformation of sexithiophenes is associated with higher crystalline density, e.g., comparing the pc values for $\mathbf{2 M}$ and $\mathbf{2 T}(0.70 \mathrm{vs}$ $0.73)$. The crystal cohesion of $\mathbf{1}$ is very close to that of the unsubstituted sexithiophene (both T6LT and T6HT). The calculated ppe difference between the two polymorphs of T6 $\left(4.1 \mathrm{kcal} \mathrm{mol}^{-1}\right)$ is smaller than that between $\mathbf{2 M}$ and $\mathbf{2 T}(13.8$ $\mathrm{kcal} \mathrm{mol}^{-1}$ ), given the different nature of the polymorphism present. However, both ppe differences are still in the range found by Gavezzotti et al. for polymorphic organic crystals at room conditions. ${ }^{9}$

II. Electrical Characteristics of the Thin Film Field Effect Transistors Fabricated with Sexithiophene 1. The quasi planar conformation and the compressed molecular packing of $\mathbf{1}$ are favorable conditions for obtaining highly ordered thin films and elevated electrical charge carrier mobilities.

It is well-known that high mobility values in semiconducting oligomer devices are obtained by careful control of the deposition procedures (substrate temperature and evaporation rate), to get a high short-range order, with the molecules arranged parallel to each other, as well as an elevated long-range order, for reducing traps of charges such as the grain boundaries. ${ }^{2 \mathrm{e}}$

TFTs fabricated by evaporating 1 at a rate of $0.1 \mathrm{~nm} / \mathrm{s}$ with a substrate temperature of $80^{\circ} \mathrm{C}$ demonstrated a charge mobility, $\mu=2 \times 10^{-2} \mathrm{~cm}^{2} /(\mathrm{V} \mathrm{s})$ (Figure 4). This value was calculated in the usual way, ${ }^{2 \mathrm{p}}$ from the saturation regime by the relationship: $\mu_{\text {sat }}=\left(2 I_{\mathrm{DS}} L\right) / W C_{\mathrm{ox}}\left(V_{\mathrm{G}}-V_{\mathrm{th}}\right)^{2}$, where $I_{\mathrm{DS}}$ is the sourcedrain current in the saturation regime; $L$ and $W$ are the channel

(9) Gavezzotti, A.; Filippini, G. J. Am. Chem. Soc. 1995, 117, 12299.

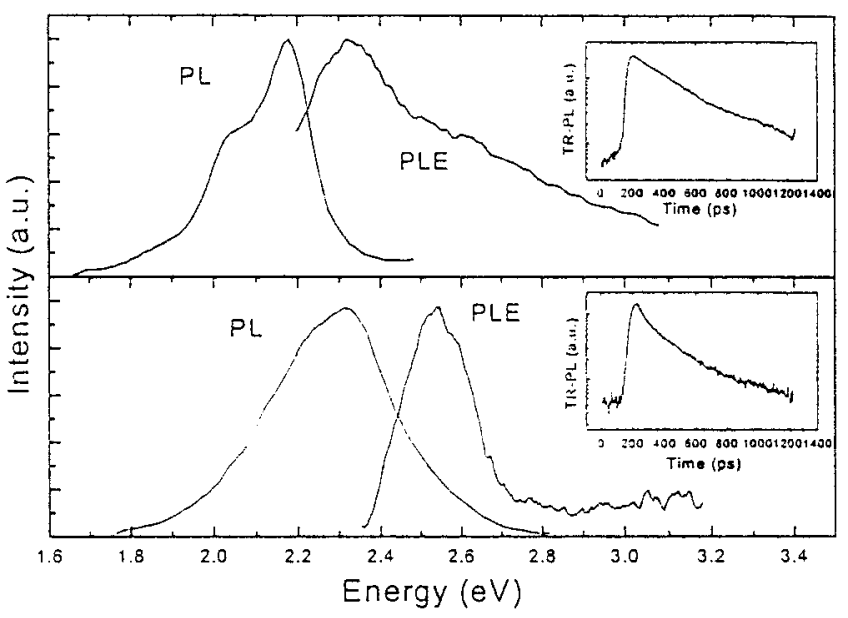

Figure 5. Continuous wave photoluminescence (PL) and photoluminescence excitation (PLE) spectra of the monoclinic (2M, bottom) and triclinic (2T, top) forms of sexithiophene 2. The insets show the temporal evolution of the PL peaks at $535 \mathrm{~nm}(2.32 \mathrm{eV})$ for $\mathbf{2 M}$ and at $566 \mathrm{~nm}(2.19 \mathrm{eV})$ for $\mathbf{2 T}$.

length and width, respectively; $C_{\mathrm{ox}}$, the oxide capacitance, $V_{\mathrm{G}}$, the gate voltage; and $V_{\text {th }}$, the treshold voltage. A similar result was obtained by calculating the mobility in the linear regime, from the relationship: $\mu_{\text {lin }}=\left(g_{\text {lin }} L\right) /\left(W C_{\mathrm{ox}} V_{\mathrm{sd}}\right)$, where $g_{\text {lin }}$ is the transconductance in the linear regime and $V_{\text {sd }}$ the souce-drain voltage.

The mobilities of TFTs fabricated with the substrate kept at room temperature were of the order $10^{-4} \mathrm{~cm}^{2} /(\mathrm{V} \mathrm{s})$, whereas, at $T=60^{\circ} \mathrm{C}$, the mobilities were of the order $10^{-3} \mathrm{~cm}^{2} /(\mathrm{V} \mathrm{s})$. At $T>80^{\circ} \mathrm{C}$ the films presented extended cracks, with loss of continuity and showed no transistor effect, probably due to a crystalline rearrangement and/or to differential thermal stresses. A detailed study of the TFTs of $\mathbf{1}$ fabricated with different geometries will be reported elsewhere.

It is worth noticing that TFTs fabricated with $\mathbf{2}$ gave much lower mobility values than those fabricated with $\mathbf{1}$, probably due to the presence of both polymorphs in the film.

III. Optical Properties of the Conformational Polymorphs 2M and 2T. Different packing modalities bring about profound differences in the optical properties of compound 2 . The optical studies were performed on single crystals of $\mathbf{2 M}$ and $\mathbf{2 T}$ by continuous wave luminescence (PL), time-resolved luminescence (TR-PL), and photoluminescence excitation (PLE). All spectra are reported in Figure 5.

Comparison of the PLE spectra shows that the HOMOLUMO energy gap of $\mathbf{2} \mathbf{M}$ is higher (and the corresponding wavelength blue shifted) by about $210 \mathrm{meV}$ with respect to that of 2T. On the basis of what is known for methylated quaterthiophenes, ${ }^{10 a}$ this difference is attributed to the more distorted conformation of the molecules constituting the monoclinic crystal. In the PL spectra, the wavelength blue shift is reduced to about $130 \mathrm{meV}$, pointing out a more similar molecular conformation of $\mathbf{2 M}$ and $\mathbf{2 T}$ in the excited state. The trend is the same as that observed for the single crystals of the conformational polymorphs of TMSQ. ${ }^{10 \mathrm{~b}}$ Owing to the mesomeric effect of the methylsulfanyl groups, the values of the emission wavelengths in TMSQ are greater than those of 2 . However, as observed for $\mathbf{2 M}$ and $\mathbf{2 T}$, the wavelength of the light emission of the monoclinic crystal of TMSQ, with a more

(10) (a) Gigli, G.; Rinaldi, R.; Lomascolo, M.; Cingolani, R.; Barbarella G.; Zambianchi, M. Appl. Phys. Lett. 1998, 72, 1013. (b) Gigli, G.; Lomascolo, M.; Cingolani, R.; Barbarella, G.; Zambianchi, M.; Antolini, L.; Dellasala, F.; Dicarlo, A.; Lugli, P. Appl. Phys. Lett. 1998, 73, 2414. 
distorted molecular conformation, is blue-shifted with respect to that of the triclinic counterpart.

The inset of Figure 5 shows the temporal evolution of the PL peaks at $566 \mathrm{~nm}(2.19 \mathrm{eV})$ for $2 \mathrm{~T}$ and at $535 \mathrm{~nm}(2.32 \mathrm{eV})$ for $\mathbf{2 M}$. A quasi monoexponential decay with time constant of $295 \mathrm{ps}$ and a nonexponential decay with a fast component having a time constant of about $120 \mathrm{ps}$ are found for the triclinic crystal and monoclinic crystals, respectively. The measurements taken when varying the temperature from $T=300 \mathrm{~K}$ to $T=20 \mathrm{~K}$ (not reported) show no dependence on temperature of the decay time of the monoclinic form, whereas in the triclinic form, an increment of the decay time of 380 ps was revealed. This can be explained by considering the statistical disorder present in the triclinic form, which makes the structure less rigid and capable of vibrating. As the temperature increases, this structural feature determines an increment of the scattering processes between electronic and vibrational excitations and a consequent reduction of PL decay time.

\section{Discussion}

Our data shows that appropriate $\beta$-methylation makes sexithiophene soluble and processable while maintaining its good electrical properties. The high charge mobility, $2 \times 10^{-2}$ $\mathrm{cm}^{2} /(\mathrm{V} \mathrm{s})$ measured with the TFT-fabricated with sexithiophene $\mathbf{1}$ is comparable to that obtained for sexithiophene in thin films. ${ }^{\text {le }}$ However, contrary to unsubstituted sexithiophene $\mathbf{1}$ is soluble in organic solvents, is easy to purify by silica gel chromatography up to the grade required for electronic applications, and crystallizes from solution at ambient temperature. At the present state of knowledge, ${ }^{2,3}$ organic molecular materials with so many favorable characteristics are scarce, thus studies aimed at optimizing TFT devices based on $\mathbf{1}$ appear to be worth the effort.

The achievement of a high charge mobility implies that a great molecular ordering is reached in the evaporated thin films of $1.2 \mathrm{c}, \mathrm{e}$ Given the single-crystal characteristics, one of the reasons for the good performance of the TFT based on $\mathbf{1}$ should be found in the close packing achieved by this oligothiophene despite the presence of one head-to-head junction in the molecular structure. According to the data reported in Table 2, compound $\mathbf{1}$ is characterized by a packing energy and a packing coefficient near those of T6. Probably, the great polarizability of the sulfur atom-which makes the geometry of thiophene rings easily deformable ${ }^{8 \mathrm{~d}}$-allows the small methyl groups of $\mathbf{1}$ to be accommodated in the thin film without dramatically disturbing the self-alignment intermolecular forces which are responsible for the high structural order observed in the thin films of T6. ${ }^{2 \mathrm{e}}$ As a consequence, also in the thin films of 1, the close proximity of nearly parallel molecular layers should lead to easy interchain hopping of electrical charges and allow achieving a high charge mobility. More detailed studies of the supramolecular organization of $\mathbf{1}$ in thin film will allow this point to be elucidated and will contribute to defining the best conditions for the optimization of TFTs based on $\mathbf{1}$.

It is worth noting that the only other $\beta$-alkylated sexithiophene whose electrical properties have been studied in detail-a $\beta, \beta^{\prime}$ dihexylsexithiophene-displayed a charge mobility below the detection limits, while the $\alpha, \omega$-dihexyl regioisomer displayed greater charge mobility than unsubstituted sexithiophene, owing to a large increase in molecular organization brought about by alkyl-alkyl recognition phenomena. ${ }^{2 b}$ Since these results were reported, $\beta$-functionalization has no longer been considered a useful means for designing processable sexithiophenes with good electrical properties.

Beyond the demonstration that it is possible to obtain processable sexithiophenes with good electrical characteristics through $\beta$-methylation, there is a more fundamental aspect of the results reported here that in our opinion, deserves some attention. Indeed, our data indicate that the conformation and the geometry of substituted oligothiophenes are predictable on the basis of the number of $\beta$-substituents and the regiochemistry of substitution. This follows from examination of the behavior of sexithiophene 2, which has two head-to-head junctions and displays conformational polymorphism.

The backbone conformation and the geometry of the fragments made by the four inner methylated rings in $\mathbf{2 M}$ and $\mathbf{2 T}$ are the same as those of TMSQ, ${ }^{8 \mathrm{e}, \mathrm{f}}$ in which the $\beta$-methylsulfanyl $\left(\mathrm{S}-\mathrm{CH}_{3}\right)$ groups have the same substitution pattern as the methyl groups in $\mathbf{2}$. The similarity of the behavior of $\mathbf{2}$ and TMSQ can hardly be considered fortuitous. It indicates that the great flexibility of oligothiophenes - the concept of "flexibility" being defined by low rotation barriers around the carbon-carbon bonds and easily deformable bond length and angles ${ }^{8 \mathrm{~d}}$ - can be governed and that a key to this governability is the regiochemistry of substitution. Apparently, the regiochemistry of substitution is even more important than the nature of the substituents themselves. It is also worth noting that the backbone conformation and the geometry of the inner methylated fragment of $\mathbf{2 M}$ are the same as those of the corresponding tetramethylated quaterthiophene with two head-to-head junctions, ${ }^{8 \mathrm{~d}}$ to an astonishing degree of precision. This suggests that four thienyl rings bearing $\beta$-methyl groups organized according to a given substitution pattern do define a structural motif containing all the "...chemical and geometrical recognition features..." 6a required for obtaining a given solid-state conformation imposed by given molecular packing characteristics.

Our assumptions about the predictability of the properties of oligothiophenes on the basis of the substitution pattern are stressed by the trend observed for the photoluminescence spectra of the single crystals of $\mathbf{2 M}$ and $\mathbf{2 T}$, a trend which is the same as that shown by the conformational polymorphs of TMSQ. In TMSQ, the frequency of light emission of the two polymorphs depends on their solid-state conformation, ${ }^{10 \mathrm{~b}}$ as observed in general for polycrystalline methylated quaterthiophenes. ${ }^{10 a}$ The monoclinic crystals of TMSQ with the more distorted molecular conformation emit light at a lower wavelength and the light emission decays with a greater rate than in the triclinic crystals, characterized by a more planar molecular conformation. ${ }^{10 a}$ Figure 5 shows that also $\mathbf{2 M}$ and $\mathbf{2 T}$ have different light emission wavelengths, with that of the former being smaller than that of the latter by an amount comparable to the difference observed for the conformational polymorphs of TQMS. Moreover, the decay rate of the light emission of $\mathbf{2 M}$ is greater than that of 2T, again as in TQMS. Clearly, the trend of variation of the photoluminescence properties of $\mathbf{2 M}$ and $2 \mathbf{T}$ is dictated by the conformation of the inner methylated fragment.

In conclusion, our data shows that the conformation and the supramolecular organization of sexithiophenes in the solid state are governed by the number and the substitution pattern of the methyl groups attached in the $\beta$-positions. Thus, $\beta$-methylation appears to be a way to orient in the desired direction the electrical and optical properties of thiophene oligomers, which are strictly related to the packing of molecules in thin films or single crystals.

\section{Experimental Section}

Synthesis of Materials. Sexithiophenes $\mathbf{1}$ and $\mathbf{2}$ were obtained by the cross coupling of the appropriate bromothienyls and thienylstannanes in the presence of $\operatorname{Pd}(0)$ catalysts (Stille reaction ${ }^{11}$ ), according to the modalities already described. ${ }^{12}$ All chemicals were purchased from Aldrich. 


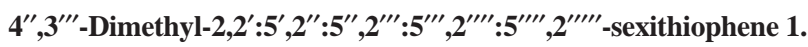

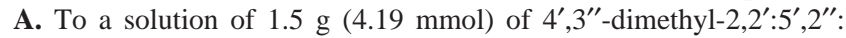
$5^{\prime \prime}, 2^{\prime \prime \prime}$-quaterthiophene ${ }^{13}$ (DMQ) in $30 \mathrm{~mL}$ of $\mathrm{CHCl}_{3} / \mathrm{CH}_{3} \mathrm{COOH} 1: 1 \mathrm{v} / \mathrm{v}$ was added $1.66 \mathrm{~g}(9.32 \mathrm{mmol})$ of $\mathrm{N}$-bromosuccinimide stepwise. The mixture was refluxed for $1 \mathrm{~h}$ and quenched with water; the organic phase separated, washed first with a saturated solution of $\mathrm{KOH}$ and then with brine, evaporated, and chromatographed on silica gel using hexane/methylene chloride 95:5 v/v as the eluent. A total of $1.75 \mathrm{~g}$ ( $81 \%$ yield) of $5,5^{\prime \prime \prime}$-dibromo-4', $3^{\prime \prime}$-dimethyl- $2,2^{\prime}: 5^{\prime}, 2^{\prime \prime}: 5^{\prime \prime}, 2^{\prime \prime \prime}$-quaterthiophene (DMQBr) was obtained as an orange solid, mp $122-24^{\circ} \mathrm{C}$. MS (70 eV, EI): m/e $516\left(\mathrm{M}^{+\bullet}\right) .{ }^{1} \mathrm{H}$ NMR $\left(\mathrm{CDCl}_{3}, \mathrm{ppm} / \mathrm{TMS}\right): 6.96$ $\left(J_{\mathrm{AB}}=3.8,2 \mathrm{H}\right), 6.94(\mathrm{~s}, 2 \mathrm{H}), 6.89\left(J_{\mathrm{AB}}=3.8,2 \mathrm{H}\right), 2.19(\mathrm{~s}, 6 \mathrm{H}) \cdot{ }^{13} \mathrm{C}$ NMR ( $\left.\mathrm{CDCl}_{3}, \mathrm{ppm} / \mathrm{TMS}\right): 138.6,137.5,135.7,130.6,128.3,127.0$, 123.6, 111.0, 15.0. B. $\mathrm{AsPh}_{3}(110 \mathrm{mg}, 0.36 \mathrm{mmol})$ was added to 46 $\mathrm{mg}(0.04 \mathrm{mmol})$ of $\mathrm{Pd}_{2} \mathrm{dba}_{3}$ in $10 \mathrm{~mL}$ of toluene, and the mixture refluxed for $10 \mathrm{~min}$. Then $1.55 \mathrm{~g}(3.0 \mathrm{mmol})$ of DMQBr dissolved in $100 \mathrm{~mL}$ of toluene was added, and the solution was warmed again to reflux. Afterward $2 \mathrm{~mL}(6.31 \mathrm{mmol})$ of commercial 2-tributylstannylthiophene was added. The mixture was stirred at reflux for $24 \mathrm{~h}$ and evaporated, and the residue was chromatographed on silica gel using hexane/methylene chloride $80: 20 \mathrm{v} / \mathrm{v}$. A total of $0.70 \mathrm{~g}(45 \%$ yield) of sexithiophene $\mathbf{1}$ was obtained as a brown microcrystalline powder, mp $163-164{ }^{\circ} \mathrm{C}$. MS $(70 \mathrm{eV}, \mathrm{EI}): m / e ~ 522\left(\mathrm{M}^{+\bullet}\right) . \lambda_{\max }\left(\mathrm{CHCl}_{3}\right)$ $=388 \mathrm{~nm} .{ }^{1} \mathrm{H}$ NMR $\left(\mathrm{CDCl}_{3}, \mathrm{ppm} / \mathrm{TMS}\right): \delta 7.22\left(\mathrm{q},{ }^{3} J_{\mathrm{HH}}=5.0,{ }^{3} J_{\mathrm{HH}}\right.$ $=1.0,2 \mathrm{H}), 7.18\left(\mathrm{q},{ }^{3} J_{\mathrm{HH}}=3.5,{ }^{3} J_{\mathrm{HH}}=1.0,2 \mathrm{H}\right), 7.07\left(J_{\mathrm{AB}}=3.8,2 \mathrm{H}\right)$, $7.025\left(\mathrm{q},{ }^{3} J_{\mathrm{HH}}=5.0,{ }^{3} J_{\mathrm{HH}}=3.5,2 \mathrm{H}\right), 7.02(\mathrm{~s}, 2 \mathrm{H}), 2.22(\mathrm{~s}, 6 \mathrm{H}) \cdot{ }^{13} \mathrm{C}$ NMR (CDCl $3, \mathrm{ppm} / \mathrm{TMS}): \delta 137.5,137.1,136.4,136.3,136.0,128.2$, 127.9, 126.7, 124.5, 124.4, 124.2, 123.7, 15.0. Calcd. for $\mathrm{C}_{26} \mathrm{H}_{18} \mathrm{~S}_{6}$ : C, 59.73; H,3.47. Found: C, 59.61; H, 3.48.

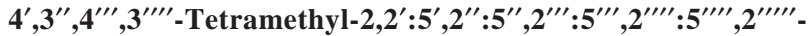
sexithiophene, 2. To a solution of $85 \mathrm{mg}(0.082 \mathrm{mmol})$ of $\mathrm{Pd}_{2} \mathrm{dba}_{3}$ in $40 \mathrm{~mL}$ of toluene was added $202 \mathrm{mg}(0.66 \mathrm{mmol})$ of $\mathrm{AsPh}_{3}$, and the mixture was refluxed for $10 \mathrm{~min}$. Then $2.90 \mathrm{~g}(8.24 \mathrm{mmol})$ of 5,5'dibromo-3,3'-dimethyl-2,2'-bithiophene ${ }^{13}$ dissolved in $30 \mathrm{~mL}$ of toluene was added, and the solution was warmed again to reflux. Afterward $5.50 \mathrm{~mL}$ (17.35 mmol) of commercial 2-tributylstannylthiophene was added. The mixture was refluxed for $45 \mathrm{~h}$, quenched with $2 \mathrm{~N} \mathrm{HCl}$, and washed with $\mathrm{NH}_{4} \mathrm{Cl}$; the organic layer was separated, dried with $\mathrm{Na}_{2} \mathrm{SO}_{4}$, and evaporated. The residue was treated twice with hexane; the hexane layer was separated, evaporated, and chromatographed on silica gel using hexane as the eluent. A total of $1.15 \mathrm{~g}$ (39\% yield) of tetramer DMQ ${ }^{13}$ was first obtained and then $0.81 \mathrm{~g}$ (36\% yield) of hexamer $\mathbf{2}$ was separated as a yellow-orange microcrystalline powder. MS (70 eV, EI): m/e $550\left(\mathrm{M}^{+\bullet}\right) . \lambda_{\max }\left(\mathrm{CHCl}_{3}\right)=370 \mathrm{~nm} .{ }^{1} \mathrm{H} \mathrm{NMR}$ $\left(\mathrm{CDCl}_{3}, \mathrm{ppm} / \mathrm{TMS}\right): \delta 7.22\left(\mathrm{q},{ }^{3} J_{\mathrm{HH}}=5.0,{ }^{3} J_{\mathrm{HH}}=1.0,2 \mathrm{H}\right), 7.17(\mathrm{q}$, $\left.{ }^{3} J_{\mathrm{HH}}=3.5,{ }^{3} J_{\mathrm{HH}}=1.0,2 \mathrm{H}\right), 7.02\left(\mathrm{q},{ }^{3} J_{\mathrm{HH}}=5.0,{ }^{3} J_{\mathrm{HH}}=3.5,2 \mathrm{H}\right)$, 7.025 (s, 2H), $7.00(\mathrm{~s}, 2 \mathrm{H}), 2.22(\mathrm{~s}, 12 \mathrm{H}) \cdot{ }^{13} \mathrm{C} \mathrm{NMR}\left(\mathrm{CDCl}_{3}, \mathrm{ppm} /\right.$ TMS): $\delta 137.4,137.3,137.2,136.6,136.3,128.2,128.1,127.8,126.8$, 126.6, 124.4, 123.6, 15.0. Calcd. for $\mathrm{C}_{28} \mathrm{H}_{22} \mathrm{~S}_{6}$ : C, 61.05; $\mathrm{H}, 4.03$. Found: C,61.19; H,4.05. Compound $\mathbf{2}$ gave rise to spontaneous crystallization of polymorphs $\mathbf{2 M}$ and $\mathbf{2 T}$ at room temperature. The crystallization always afforded both forms: yellow crystals, $\mathbf{2 M}, \mathrm{mp}$ $145-146^{\circ} \mathrm{C}$, and orange-red crystals, $2 \mathrm{~T}$, mp $150-151^{\circ} \mathrm{C}$, which could be separated by hand. The relative amount of both types of crystals depended on the solvent used.

X-ray Crystallographic Studies. Crystals of all compounds were grown by slow evaporation of 2-propanol solutions at room temperature. All X-ray measurements were carried out on a rotating-anode Siemens P4RA-M18X diffractometer at room temperature by the $\theta-2 \theta$ scan technique, and using graphite-monochromated Mo K $\alpha$ radiation $(\lambda=$ $0.710609 \AA$ A). In all cases, intensity data were corrected for Lorentz and polarization effects, but not for absorption in view of the low absorption coefficients and almost isotropic crystal dimensions. All structures were solved by direct methods (SHELX86 program), and

(11) Stille, J. K. Angew. Chem., Int. Ed. Engl. 1986, 25, 508

(12) Barbarella, G.; Zambianchi, M.; Sotgiu, G.; Bongini, A. Tetrahedron 1997, 53, 9401.

(13) Van Pham, C.; Burkhardt, A.; Nkansah, A.; Shabana, R.; Cunnigham, D. D.; Mark, H. B., Jr.; H. Zimmer, H. Phosphorus, Sulfur, Silicon Relat. Elem. 1989, 46, 153. were refined through full-matrix least-squares calculations based on $F^{2}$ (SHEXL93) for all unique reflections. ${ }^{14,15}$

Compound 1: $\mathrm{C}_{26} \mathrm{H}_{18} \mathrm{~S}_{6}$; orange yellow, air stable crystals. The one selected had approximate dimensions $0.25 \times 0.15 . \times 0.15 \mathrm{~mm}$. Unit cell dimensions were obtained from least-squares fit to the setting angles of 35 automatically centered reflections in the $1-17^{\circ} \theta$ range. Crystals are monoclinic, space group $P 2_{1} / n$, with $a=12.203(1), b=7.552(1)$, $c=25.833(3) \AA, \beta=98.34(1)^{\circ}$, and $V=2355.5(6) \AA^{3}$. For $Z=4$, the calculated density is $1.475 \mathrm{mg} / \mathrm{m}^{3}$. A total of 5453 reflections were collected in the $1.76-25.0^{\circ} \theta$ range at a power source of $52 \mathrm{kV}$ and $120 \mathrm{~mA}$. No decay or absorption correction was applied $(\mu=0.595$ $\left.\mathrm{mm}^{-1}\right)$. The intensities were averaged to 4090 unique data $\left(R_{\text {int }}=0.034\right)$, of which 2497 have $I \geq 2 \sigma(I)$. All non-hydrogen atoms were refined anisotropically, and $\mathrm{H}$ atoms were constrained to ride in calculated positions on atoms to which they are bonded, with thermal parameters set 1.2 times the equivalent isotropic parameters of the bonded atoms. Least-squares refinement of 295 parameters led to final $R$ and wR2 values of 0.0629 and 0.1676 for reflections with $I \geq 2 \sigma(I)$, and of 0.1143 and 0.2011 , respectively, for all reflections. The weighting scheme used throughout was $w=1 /\left[\sigma^{2}\left(F_{\mathrm{o}}{ }^{2}\right)+(0.0900 P)^{2}+3.2998 P\right]$, where $P=$ $\left(F_{\mathrm{o}}{ }^{2}+2 F_{\mathrm{c}}{ }^{2}\right) / 3$, and the final goodness-of-fit on $F^{2}$ was 1.032 . The largest peak and hole differences were 0.441 and -0.542 e $\AA^{3}$, respectively.

Compound 2M: $\mathrm{C}_{28} \mathrm{H}_{22} \mathrm{~S}_{6}$; yellow green, air stable crystals. The one selected had approximate dimensions $0.35 \times 0.25 . x 0.20 \mathrm{~mm}$. Unit cell dimensions were derived from least-squares fit to the setting angles of 40 automatically centered reflections in the $5-18^{\circ} \theta$ range. Crystals are monoclinic, space group $C 2 / c$, with $a=42.629(3), b=7.778(1)$, $c=7.867(1) \AA, \beta=98.04(1)^{\circ}$, and $V=2582.7(4) \AA^{3}$. For $Z=4$, the calculated density is $1.417 \mathrm{mg} / \mathrm{m}^{3}$. A total of 3345 reflections were collected in the $2.66-27.0^{\circ} \theta$ range at a power source of $52 \mathrm{kV}$ and $80 \mathrm{~mA}$. No decay or absorption correction was applied $(\mu=0.546$ $\left.\mathrm{mm}^{-1}\right)$. The intensities were averaged to 2797 unique data $\left(R_{\mathrm{int}}=0.032\right)$, of which 2117 have $I \geq 2 \sigma(I)$. All non-hydrogen atoms were refined anisotropically, and $\mathrm{H}$ atoms, located in $\Delta F$ maps, isotropically, with common temperature factors for those bonded to thienyl rings or to methyl groups. Least-squares refinement of 189 parameters led to final $R$ and wR2 values of 0.0479 and 0.1244 for reflections with $I \geq 2 \sigma(I)$, and of 0.0695 and 0.1632 , respectively, for all reflections. The weighting scheme used throughout was $w=1 /\left[\sigma^{2}\left(F_{\mathrm{o}}{ }^{2}\right)+(0.0611 P)^{2}+4.2013 P\right]$, where $P=\left(F_{\mathrm{o}}{ }^{2}+2 F_{\mathrm{c}}{ }^{2}\right) / 3$, and the final goodness-of-fit on $F^{2}$ was 1.013 . The largest peak and hole differences were 0.634 and -0.630 e $\AA^{3}$, respectively.

Compound 2T: $\mathrm{C}_{28} \mathrm{H}_{22} \mathrm{~S}_{6}$; orange yellow, air stable crystals. The one selected had approximate dimensions $0.33 \times 0.30 . \times 0.25 \mathrm{~mm}$. Unit cell dimensions were obtained from least-squares fit to the setting angles of 31 automatically centered reflections in the $4.5-17.5^{\circ} \theta$ range. Crystals are triclinic, $P \overline{1}$ space group, with $a=7.195(2), b=7.680$ (2), $c=11.438(3) \AA, \alpha=99.47(2), \beta=91.62(2), \gamma=107.08(2)^{\circ}$, and $V=626.9(3) \AA^{3}$. For $Z=1$, the calculated density is $1.419 \mathrm{mg} /$ $\mathrm{m}^{3}$. A total of 3047 reflections were collected in the $1.8-26.9^{\circ} \theta$ range at a power source of $12 \mathrm{kV}$ and $100 \mathrm{~mA}$. No decay or absorption correction was applied $\left(\mu=0.563 \mathrm{~mm}^{-1}\right)$. The intensities were averaged to 2460 unique data $\left(R_{\text {int }}=0.024\right)$, of which 2034 have $I \geq 2 \sigma(I)$. After anisotropic refinement of all non-hydrogen atoms, unusually high atomic thermal parameters and relevant residuals in $\Delta F$ maps provided evidence of statistical disorder involving outer thiophene rings. They assume two opposite orientations (anti or syn), with respect to the adjacent rings, differing by a rotation of about $180^{\circ}$ around the interring $\mathrm{C}-\mathrm{C}$ bond. Least-squares refinement of site occupancy factors led to the value of 0.790 (3) for atoms at major sites (anti conformation), and, obviously, 0.210 (3) for the opposite conformation. All non-H atoms with full or major occupancy factors were refined anisotropically. Non-H atom at minor sites were refined isotropically with one common temperature factor. Furthermore, bond length constraints were applied to atoms with lowest occupancy $(\mathrm{C}-\mathrm{S}=1.70 \AA, \mathrm{C} 2 \mathrm{~A}-\mathrm{C} 3 \mathrm{~A} *=1.375$ $\AA, \mathrm{C} 3 \mathrm{~A}^{*}-\mathrm{C}_{4} \mathrm{~A}^{*}=1.415 \AA$ ). The hydrogen atoms with full or major occupancy were located in $\Delta F$ maps and were refined isotropically, with common temperature factors for those bonded to thienyl rings or to methyl groups. Those at minor sites were added to the model in calculated positions. Least-squares refinement of 203 parameters led 
to final $R$ and wR2 values of 0.0388 and 0.0916 for reflections with $I$ $\geq 2 \sigma(I)$, and of 0.0111 and 0.11164 , respectively, for all reflections. The weighting scheme used throughout was $w=1 /\left[\sigma^{2}\left(F_{0}\right)+(0.0468 P)^{2}\right.$ $+0.2496 P]$, where $P=\left(F_{\mathrm{o}}{ }^{2}+2 F_{\mathrm{c}}{ }^{2}\right) / 3$, and the final goodness-of-fit on $F^{2}$ was 1.053 . Largest difference peak and hole were 0.328 and -0.448 e $\AA^{3}$, respectively.

ORTEP drawings of the structures of $\mathbf{1}, \mathbf{2 M}$, and $\mathbf{2 T}$ are presented in Figures 1-3. Tables of positional and thermal parameters, bond distances and angles, torsion angles, shortest intermolecular distances, selected least-squares planes, and a stereoview of the crystal packing are provided as Supporting Information.

Packing potential energy (ppe) calculations were carried out using a semiempirical approach, ${ }^{16}$ based on an atom-atom potential energy method. ${ }^{17}$ In the case of $\mathbf{2 T}$, characterized by structural disorder, the calculations were carried out on an ordered model retaining the prevailing conformation of the disordered fragment. Packing coefficients (pc) were calculated according to the expression pc $=Z V_{\text {mol }} / V_{\text {cell }}$, where $Z$ is the number of molecules in the unit cell.

Thin Film Transistors. Thin film transistors (TFT) were fabricated by vacuum evaporation $\left(1 \times 10^{-6}\right.$ mbar $)$ on oxidized $n$-doped silicon wafers. Two different contact configurations were used ("bottom" and "top"). In the bottom configuration the Au source-drain and gate contacts were delineated by photolithography, with a channel width $(W)$ of $10 \mu \mathrm{m}$ and a channel length $(L)$ of $1.2 \mathrm{~cm}$. In the top

(14) Sheldrick, G. M. Acta Crystallogr. Sect. A 1990, 24, 311.

(15) Sheldrick, G. M. SHELXL93. Program for the refinemnt of crystal structures. University of Göttingen, Germany, 1993.

(16) Gavezzotti, A. J. Am. Chem. Soc. 1983, 105, 5220.

(17) Persin, A. J.; Kitaigorodsky, A. I. The Atom-Atom Potential Method; Springer-Verlag: Berlin, 1987. configuration (shown in Figure 4) the contacts were obtained by an Au evaporation through a stencil. In this case, $W$ was of the order 8.2 $\mathrm{mm}$ and $L$ was $0.42 \mathrm{~mm}$. In both cases the oligomer was evaporated through opportune stencils. Whereas in the bottom configuration even the gate contact was on the front of the wafer, in the top configuration the rear of the wafer acted as the gate contact (after etching the $\mathrm{SiO}_{2}$ film and an Al film deposition). During the evaporation, the TFT temperature was controlled by heating the substrate on which they were mounted. The evaporation rate was of the order of $0.1 \mathrm{~nm} / \mathrm{s}$. The electrical characterizations were performed at room temperature in air, using a 4145B Hewlett-Packard semiconductor parameter analyzer.

Optical Studies. PL measurements were carried out using an argon laser operating at $363 \mathrm{~nm}$, whereas the PLE measurements were performed with a $120-\mathrm{W}$ tungsten lamp monochromized by a $0.5-\mathrm{m}$ single monochromator. The signal was detected by a $2-\mathrm{m}$ double monochromator equipped with cooled photon counter. Measurements of TR-PL were made by a mode-locked Ti-sapphire laser generating light pulses of $2 \mathrm{ps}$ in duration at a repetition rate of $82 \mathrm{MHz}$. The luminescence was spectrally dispersed by a $24-\mathrm{cm}$ focal length monochromator coupled to a streak camera, equipped with a twodimensional CCD. The overall time resolution was about 10 ps.

Supporting Information Available: Tables of positional and thermal parameters, bond distances and angles, torsion angles, shortest intermolecular distances, selected least-squares planes, for compounds $\mathbf{1}, \mathbf{2 M}$, and $\mathbf{2 T}$, and a drawing of the disorder model for $\mathbf{2 T}$. This material is available free of charge via the Internet at http://pubs.acs.org.

JA9916512 